\title{
Increasing Air Traffic Effect on Developing Regional and Mega-hub Airports in Asia-Pacific Region
}

\author{
Kosuke Sendo \\ Boeing 777 Fleet Flight Operations Department, Osaka Aviation Technical College, Osaka, Japan \\ Email address: \\ kosukesendo@gmail.com \\ To cite this article: \\ Kosuke Sendo. Increasing Air Traffic Effect on Developing Regional and Mega-hub Airports in Asia-Pacific Region. American Journal of \\ Theoretical and Applied Business. Vol. 7, No. 3, 2021, pp. 65-71. doi: 10.11648/j.ajtab.20210703.12
}

Received: July 13, 2021; Accepted: July 27, 2021; Published: August 2, 2021

\begin{abstract}
With the skies busier than ever, air traffic needs to be addressed properly because it affects various other determinants of a national economy. The commercial flights are set to double in the next decade, the eventual method to tackle the problems raised due to air traffic in airport management systems need upscaling. It has to be made into consideration that aviation or air traffic plays a vital role in nourishing and strengthening the lifestyle of communities as well as the local economy in the form of employment opportunities, a boost to the GDP, educational services, and an uplift to the quality of lifestyle. The everyday increase in the rate of customers' demand for air travel services has highlighted the problem of the need of better utilization of air space. With the induction of new types of unmanned and autonomous aircrafts the need of revamping the system is also necessary. Recommendations on this matter are discussed further. In Dec 1903, the air age arrived, when the Wright Brothers try to fly and succeeded the aircraft above the ground surface i.e., more than 120 feet at Kitty Hawk, N.C., the U.S state. As time passed the number of aviation industry increase the numeral amount of aeroplane or aircraft day by day, as a result, the rate of traffic escalates exponentially. The main equitable of aviation is to provide the opportunities regarding the less time effectiveness and comfortable environment to establish a destination. On the other hand, it has also a dependency on the "economy" (i.e, less expensive traveling). The above-mentioned postulates show the increase in the rate of customers demanding a more suitable air traveling services, which also increases the number of the aeroplane and directly related to the increase in the development of airports. Thus, for such a problem solution it requires more outstanding services and control of air traffic. This chapter discussed the research objectives by linking the rate of air traffic control and the literature associated with objectives.
\end{abstract}

Keywords: Airport Development, Air Traffic, Asia-Pacific, COVID

\section{Introduction}

Asia Pacific quick development in the aviation business has evolved itself as the region with great and fastestgrowing in the world. The development in the Asia Pacific is relied upon to remain strong, conjecture to proceed as the world's most noteworthy development area well beyond 2020. The countries that come under the Asia-Pacific region are more divergent economically, socially and politically than the countries of other regions. Regardless, avionics infrastructure isn't staying up with this development. Huge numbers of the Asian center points are now working over their arranged limit, bringing about a fast acceleration of delays since 2010. Current designs for developing mega- hub airports are not successful from a cost perspective and will neglect to keep up with the demand. This chapter includes all the research objectives to determine whether they have been fulfilled or not.

\section{Discussion}

\subsection{Determining the Reason and Factors Which Have Increased the Air Traffic and International Flights in the Asia-Pacific Region}

It has been discussed that air traffic in the Asia Pacific region and especially Japan has increased due to various factors. Among various factors contributing to increasing air traffic, previous studies have determined the reason for changing consumer demand. Apart from this, other factors 
that affect air traffic include the variation in living standards. It has been noticed that nowadays, the matter of concern and option for passengers are changing as they are more satisfied to spend money on travelling. Referring to the changes in economic class, the collected data revealed that changes in economic distribution lead to a change in the overall employment criteria. This affects the overall consumer market and thus is considered as the reason or factor which have increased the air traffic and international flights in the AsiaPacific region. With the help of primary and secondary data, some other factors have also been highlighted in conducting this study, including the sociodemographic and demographics factors. The majority of interviewees have shared the importance of socio-economic factors because the trends and consumer's perspective to focus on flights help to increase the air traffic. Other than this, it has been found that the majority of users are now getting environmental awareness that can be concluded as the trigger factor for the passengers. Hence, this is one of the factors to increase air traffic rates in the Asia Pacific region. With the help of environmental awareness and increasing development of the aviation sector, it becomes easy for the passengers to upgrade the rates of air traffic. Not limited to this, the collected data assisted to accomplish the discussed objective and shared that improvement in economies is one of the reasons for an increased air traffic rate. One of the examining trends shared those developing countries now prefer to travel more and increase the rate of air traffic as there is an increased rate of job opportunities that have also been observed.

Moreover, it has been claimed by some studies that the living standards of people in Japan are also contributing important role to have increased availability of jobs or employment chances. It has resulted that betterment in financial and economic conditions helps to increase the air traffic rate [1]. Added to this, the evaluation of primary data revealed fluctuation in the cost of travel rates especially when there is affordable flight cost is helpful to increase the consumer's demand to avail of the air flight services. The data collected from primary criteria found that a downtrend in the cost per trip is counted as the beneficial factor to consider as this factor showed a link with economic factors. Similar to this, it has also been discussed those affordable plans and arrangements of air trips are playing an important role to increase air traffic in the Asia Pacific region.

\subsection{The Impact of Air Traffic on Airport Development}

However, it can be identified that the innovation of interaction and transportation structures along with the global development of economic activity has resulted in the world to "shrink" both temporally and spatially [2]. Whilst, the result of their upsurge cross-border associations and exchange affiliations, researchers of urban structures evaluate cities and regions as part of the whole world of competing centers. Thus, globalization and development of airport mean that cities associated with the trio and its cores, the United States, Japan and European Union (EU) are wide-open to multinational rivalry and therefore it needs to vigorously grow the character- istics that participate for the vivacity of their region [3]. Accordingly, to the respondent, it can be extracted that air traffic has an important impact on airport development. Since the idea of making or planning an airport comes from the increased demand of people who desirably want to travel by air than any other means of transportation. The people who are keen to accommodate the air travel make the room for the development of vast and convenient infrastructure that could benefit them at the time of need. It cannot be wrong to say that as the air traffic increases, it ultimately gives birth to the development of airport infrastructure.

Preceding this, it has been discussed that several business operations such as imports and exports of countries rely on air travel and stress upon the need for airport development. Collectively, the exertion of business operations leads to the development of airport infrastructure for the proper management of business operations. Reportedly, another impact that has been discussed is the satisfaction of customers upon the provision of better services and a good infrastructure environment [4]. Commuters tend to be satisfied if they are given proper excellent environment, on-time arrival and departure of flights, better in-flight services in terms of snacks, etc. The provision of proper facilities to the commuters helps in building the confidence of people upon the provider which will strengthen the future commitment in terms of travel. They are likely to be happier upon having all these facil- ities, however, deprecation any of the above facility may lead to adverse effects. Moreover, a worth-mentioning fac- tor that has been discussed is the economic impact of airport development. It has seen that air traffic and air travel is a strong means of the regulation and circulation of the economy of several countries that tend to be connected through the air. People travel from one place to another by means of air resulting in the flow of the economy of several countries. Hence, the airport development gives off a positive impact on economic development. An additional impact that has been discussed is the enhancement of lifestyle of individu- als due to the development of the airport. Considering the upgradation or establishment of an airport, there would be employment opportunities as well through which people get jobs and benefits. As a result of which, the lifestyle of people will be raised that will help in nourishment of a better society.

Moreover, it has been discussed that there are several negative impacts of air traffic on the airport development, among which the lack of space and ground for landing or taking off of aeroplanes tops the list. Due to the increased demand for air travel, a magnificent number of people tend to travel, resulting in the increased need of having more aircraft. The greater the number of aircraft, the greater will be the need for more runways in order to have more than one flight for taking off or landing purpose. This factor adds to the issue of having less space for the landing of aeroplanes. Another negative impact that was discussed is the accelerated number of accidents. Focusing on the need for catering to the congestion of people in the form of providing excess numbers of aircraft, lead to the major issue of accidents. Since it could 
become difficult to track an excessive number of aeroplanes and in case of any emergency circumstances, there might be no space for the aeroplane to be landed which can lead to the increase in a number of accidents and fatal miseries. This is can be seen that there are reportedly a large number of accidents that took place in the past few years which was a result of increased demand in air travel.

\subsection{Need for Regional Development of Airports in Japan}

The next question has been extracted the theme to identify the impact of air traffic on airport development in the Asia Pacific region by which relevant data can be gathered to accomplish the designed objectives. It has been deter- mined that airport development is all about "connectivity and growth" [5]. Especially, in this year, people have experienced a strong and durable channel of airport collaborations throughout the world and there must be a complete constructive viewpoint for the "global aviation industry" [6]. The major role that has been played in this industry is by the reasonable oil rates and recovery of the economic factor, which is still constructing (although gradually).

Nonetheless, the aviation market seems to have turned a corner, associated with demand increasing and airline productivity and effectiveness recurring. Yet, there are some drawbacks too, which offer the development through embryonic markets that do not fulfil the expectation or give optimal results [7]. Certainly, the aviation market has been returning along with various stakeholders and shareholders are anxious that present asset charges are approaching their preceding ultimate times and they might be vulnerable to correct if economic situations vary [8]. Nevertheless, if charges for the fuel in developing markets endure, the long-term forecast for airport revenue is durable and efficient. It is particularly accurate that gives the shortage of assets accessible when relating to the demand through numerous classifications of the shareholders.

\subsection{The Regional Development of Japan Airports as a Result of Increased Air Traffic in the Region}

Whilst, in various states considered as the individual airport, makes these airports a comer stone of diplomatic associations as the essential entry to the nation, small airports might play a helping role for busier ones associated with a specific upsurge in consumption through "LCCs (Low-Cost Carriers) that have attained durable development and existence in current years. If there are small in dimension, these airports should fulfil international standards within airport function and safety measures as well.

For instance, "Mongolia's Chinggis Khaan International Airport" situated in its capital Ulaanbaatar is supposed to be a small airport with a yearly traffic of around 1.5 million travelers, yet being Mongolia's solitary international airport means it helps as the point of the entrance within the country. However, for interior Mongolia, regardless its overland connections with adjoining China and Russia, "Chinggis Khaan International Airport" occurs as the sole point of interaction through the air, enabling as the repository for the individuals and products through airways that help quick, mass conveyance through distant places.

It can be identified that airports, airlines, airport on-site businesses (retail and restaurants), manufacturers of aircraft and air navigation facility earners hire around 302,000 individuals in Japan. Moreover, through purchasing products and services through local dealers the sector reinforced other 315,000 jobs. Therefore, the industry is projected to help further 236,000 jobs by the salaries it gives to the workforce that are consequently spend on consumer products and services. Nonetheless, overseas travelers coming through the air to Japan, who invested their good amount in the local economy, are projected to help an added 565,000 jobs [9]. Therefore, in other words, it can be determined that the regional development of Japan airports could help their workforce too for sustaining their jobs and making progress in their professional lives. However, if the employees of the firm are satisfied then eventually they will strive to target more customers, which means more revenue generation for the firm.

\subsection{The Challenges of Airport Development That You Have Been Considered in High Air Traffic Regions Like Japan}

Moreover, it can be analyzed that the association between traffic and GDP growth is significant whilst discussing aviation industry thoroughly. It can be identified that usually management and government have sustained their concentration on the most persistent concerns impacting global aviation markets [10]. Considering this factor, the aviation industry does not often operate in segregation; whereas on the other hand, it is indissolubly associated with global- ization, tourism, national competitiveness and regional eco- nomic development. Thus, these associations have been con- sidered in order to appropriately conduct data analysis for the study [11]. Nonetheless, connectivity still attains proper and complete attention, given that it carries the heart of the worth offered through the aviation market towards the wider economy; whilst, it is the extent of the wellbeing of the airport, a region, and a city. Besides, it can be examined that new stakeholders will endure entering the aviation infrastructure market, pursuing to exploit regional prospects in order to enlarge their interests and gain the benefits that connectivity carries.

\subsubsection{Role in the Revitalization of Regional Tourism and Industry}

However, it can be identified that help as the main and important engine for vitalizing regional travelling and market that could be recognized as the major roles predicted of small and developing airports. Considering the hubs of exchange, local airports often play a significant role in ascertaining regional tourism and demands, which enable the emergence of rural economies along with the job formation, and expanding an overconcentration of individuals and products flowing merely into major cities and capitals [12].

Whereas, approximately $379,000 \mathrm{~km}^{2}$ of Japan's region is 
surely not huge, as this area entails around 96 airports. Through around eight of the 96 have yearly traffic beyond 11 million travelers, mostly enduring airports attend 5 million and will be considered as small, regional airports through international standards [13]. By the "Ministry of Land, Infrastructure, Transport and Tourism' Japan Tourism Agency" Japan is presently responsible for numerous enterprises that aim to become a "tourism-oriented country" determined for the main economic undulation impact of tourism through creating demand throughout the world, involving rapidlydeveloping Asia [14]. Nevertheless, significant in being a tourism-oriented country is elevating regional economics and generating vivacious native communities by every area combined for the efforts to emerge innovative tourist fascinations and appeal a wide range of travelers.

The present procedure of globalization is classified through progressively interrelated flows of individuals, products and asset, information and collaborations throughout the world. This lead to the quick innovations associated with communication and transport structures, therefore, the world has been said to be "shrinking". Nonetheless, it results towards a variation in traditional geographical methods for perceiving the process effectively, in which urban study the slogan "from space to place" has been created.

Additionally, "global cities" emerge as places where operations, information and activities are increasingly focused. The complicated linkage amongst urban development and globalization is regarded as an important topic for urban system study. Whilst, the upsurge cross-border associates and exchange affiliations, and cities have been inferred as part of the whole world associated with opposing centers.

\subsubsection{Role of Airports in Social an Economic Transformation}

The researcher also identifies how the airport business market and its assessments that have been impacted as the aviation industry supports some new outlines of development. It also presents high evaluation predicts for some European airports coming to the market advice that preceding expectations associated with airport valuation might value re-consideration [15]. However, the early transactions through such markets as Japan and the Philippines develop, so the valuation could be done effectively in data analysis.

It can be examined that as Japan moves towards 21 st century, predictions are that societal, economic and cultural and various activities entailing the standards of living of the Japanese people that will be a development by brusquer and more several exchanges with some other nations as compared to ever before [16]. Considering this age progressively develops, there will be a theatrical upsurge within the importance of aviation, which is considered to be the most efficient ways of enabling smooth interactions of individuals and possessions [17].

Nonetheless, an analytical theme for the quest of Japan to endure for attaining stable and sustainable social and economic emergence; meanwhile managing and regulating its position within the international community will focus on promoting the appropriate emergence of airports able of countering to the demand of aviation [18]. Correspondingly, it will be specifically accurate of the global hub airports and central domestic airports required to help as the planned bases within the complete network, necessitating every impending struggle to assure that the airports, as they often do not develop because of the bottlenecks within this development [19].

In accordance with Japan's objective for airport emergence, plans need to be thoroughly developed through various years to the current date [20]. Whilst, the present "Sixth Five-Year Airport Development Plan" ending in 1995 the "Seventh Five-Year Airport Development Plan" has been enlisted to continue with this organized and stable emergence of airports in Japan.

\subsection{The Impact of COVID on Airport Development}

Considering the answers and justifications of the respondents, the major and common answer that was provided was based on the lack or insufficiency of aircraft handling especially focusing on the pandemic situation of the world due to COVID-19 [21]. No doubt, it is not right and appropriate to travel in this condition, yet proper and complete safety regulations should be provided to the management and tourists as well [22]. For instance, properly managing social distancing, wearing masks, carrying sanitizers, using disposable plates, glasses, spoons, etc. However, one of the respondents said that in the overall working criteria, there are considerable challenges faced by the AAPA conference that reflected the lack of terminal facilities, runways, poor airspace management. In this manner, I found it important to develop the infrastructure of the airport in the region like Japan.

On the contrary, one respondent interprets that it is necessary to increase the airport revenue and mitigate the overburden of passengers by airport development on the regional level. Nonetheless, it is important to alleviate the burden of travelers through airport emergence based on the regional extent. It is associated with developing airport management for regional travelling. Usually, people do not prefer to travel within the city or region and the reason behind this is poor management of the aircraft industry.

Whilst, one participant examines that it has been cleared that the most highlighted reason for the lack of airport development is the lack of capital investment nature of airport and immense destruction of aviation infrastructure that is why it has been found that it is necessary to show strict concern towards the regional development of Japan. However, it can be determined that main focus should be on the capital investment of the airport of Japan, especially towards the regional development, which will eventually increase the interest of the travelers and ensure that individuals are satisfied with the travelling facilities provided by the airport management.

However, air travelling and tourism somehow subsidize approximately 12 per cent of global GDP and assist around 320 million jobs throughout the world [23]. Whilst, considering the analysis of IFC, airports could play an important part in domestic economies, for instance, Jamaica might help 
in tracing around $12 \%$ of its services towards the direct and indirect and persuaded impacts of the "Montego Bay Airport" that has attained funding through IFC.

Whilst, because of speedy and drastic changes throughout the world and the aircraft industry, ACI endures to intermittently revise the effect of COVID-19 associated with the business of the airport. On 5th May 2020, ACI World evaluates a decrease of around 2 billion travelers at international level considering the second quarter of 2020 and around 4.5 billion passengers for all of 2020 [5]. Whereas demonstrating about the economics, airport profit cricks have been paralyzed through the unparalleled reduce within aviation and commercial measures. Therefore, the predicted failure "to- tal airport revenues" associated with an international scale is predicted to be around $\$ 40$ billion (USD); thus, in the second quarter was around $\$ 96$ billion for 2020 .

It can be identified that airports should endure completing their capital expenditures restrictions because they often continue to classify through mainly high fixed prices that are essential for preserving and functioning with the infrastructure element of the airports, involving taxiways, runways, parking stands, terminal buildings and aprons [7]. Thus, the impact of COVID-19 resulted in an existential chal- lenge for airports and the aviation industry at large scale. In addition, airports have implemented instant actions for managing the lockdown situation as demonstrated by ACI World's currently-released "Airport-Operational Practice - Examples for Managing COVID-19" that determine these measures implied at main international airports, collected through ACI's membership [24]. Moreover, ACI has re- leased an appropriate roadmap for the assistance for airport industry retrieval purpose in the result of COVID-19 situation [25]. The "Policy Brief - COVI-19: Relief Measures to Ensure the Survival of the Airport Industry" demonstrates incomparable to offer policymakers with an inclusive toolkit of outcomes in order to assure that aircraft industry could be continued by the emergency and place the groundwork for the recovery phase.

\subsection{Impact on Passenger Traffic}

Through analysis, it can be determined that the coronavirus situation has decreased passenger traffic throughout the world. Nonetheless, the interruption started in AsiaPacific, yet the speedy spread of the infection along with the suppression procedures was implied in return, such as suggestions and implementation by the administration in order to neglect travelling and airport closings, which has resulted in 23 per cent decrease in global air traffic identified in February and 50 per cent was observed in March [25].

\subsection{Impact on Revenues}

It can be analyzed that an unexpected reduction in air traffic has resulted to meet the paralysis of both "aeronautical and non-aeronautical profits" [26]. However, the airlines reduce their capacity, thus the aeronautical revenues airports often attain through airlines, for example, charges for landing associated with aircraft and security charges, which will eventually fall [5]. As people have stopped travelling because of the pandemic, non-aeronautical profits resulting through airports' parking services, hotels or duty-free shops along with plummets.

Following ACI, total airport revenues fell through 33\% throughout the world in "Q1 2020" that was around \$15 billion and it goes through 92 per cent in "Q2 2020" which is equal to around $\$ 40$ billion [5]. Therefore, planned estimations for 2020, as a complete, demonstrate that around 50\% within airport revenues (to $\$ 96$ billion) will be compared to pre-COVID-19 estimations.

Many airports were not closed because of their cargo operations that must offer some release to the airports. Nonetheless, cargo operations were impacted through airlines' capacity reduces because cargo usually travels within the belly of traveler aircraft. Meanwhile, the outcome is affiliated with both capacity and demand for air cargo that was reduced in February 2020, as the ultimate of COVID-19, although the prices charges by airlines were quite costly. Thus, considering any case, cargo profits elaborate merely a small part of total profits for airports (less than 9 per cent).

Additionally, ACI is recognized as the major part of "ICAO's Council Aviation Recovery Task Force (CART)" that is encompassed of several Member States, international firms, i.e. "World Health Organization (WHO)" and industrial bodies. The main focus is that airports are regarded as the mandatory engines of economic development, creation of wealth and employment [24]. Therefore, ACI initiates to upkeep and update its associates by the global concerns and to do its part in creating a successful and strong aviation industry.

\subsection{Upcoming Challenges}

The future forecasts of airlines along with structural modification in demand might aggravate the present condition [7].

1) The financial wellbeing of airlines: Impending airline insolvencies present a fundamental challenge for airports, specifically for the airports, which assist as hubs to struggling airlines.

2) Structural demand change: airports are expected to perceive and observe structural change within demand through the economic crisis, which will follow the SOPs and pan- demic situation due to COVID-19. Nevertheless, the performance of the airports' will endure being impacted through the "lower-thanexpected GDP growth" throughout the globe after coronavirus.

\subsection{Revenue Streams}

It has been identified that anchor airlines that are recognized as the largest and major shares of traffic at the airport and often use it as a hub characteristically subsidize the most important part of airport profits. However, airports occupy commercial associations with both firm and tourists and create two major kinds of revenue streams: 
1) Aeronautical: waged by the airlines and travelers for using the airport services, for instance, parking, landing, passenger fees and transfer fees. Whilst, these accounted for around 55 per cent of airports' revenue observed in 2017.

2) Non-aeronautical: revenue derived through retail enterprises, which involve car parking, duty-free shops, food and beverages, promotions, and rental car concessions. Nonethe- less, it enables for diversifying revenue streams for the air- ports, yet it accounted for around 39 per cent of the revenues in 2017.

\section{Conclusion}

The given chapter has highlighted discussion section of the given study. The title of the given research study is to investigate the impact of Air traffic in Asia Pacific region and its probable impact on the regional development of airports. In previous chapter, the researcher has discussed the analysis part and based on that part this chapter has conducted a detailed discussion. Discussion is divided into several subsections for example, in first section the researcher has dis- cussed issue of determining the reasons and factors which has caused increased Air traffic in the region. In this section the researcher has thrown light on the findings of interviews and align the findings with the outcomes of previously held research studies. Additionally, the researcher has also discussed the impact of Air traffic on airport development in the region as well as need of development. For example, increased Air traffic and limited capacity of available airports in the region are causing other kind of issues due to which airport and aviation industry is facing several difficulties. Therefore, authorities have to pay attention on development of airports including domestic as well as international airports. Another section of this study has also identified and discussed challenges which the regional airports has fac- ing such as reduced space for landing, security concerns, international flights connectivity and international flight hubs etcetera. Further, impact of COVID 19 pandemic and related factors are discussed such as restriction in air travel, management of social discussion on airport as well as in flights, the increased cost of precautionary measures which airports have taken in order to sustain their flight operations in the times of COVID 19 crises.

\begin{tabular}{|lccc|}
\hline & $\begin{array}{c}\text { Forecasted } \\
\text { (pre-COVID-19) }\end{array}$ & $\begin{array}{c}\text { Estimated under } \\
\text { (COVID-19) }\end{array}$ & \% Change \\
\hline Africa & 4.300 & 2,100 & $-51.2 \%$ \\
\hline Asia-Pacific & 49,900 & 20,500 & $-58.9 \%$ \\
\hline Europe & 59,300 & 22,200 & $-62.6 \%$ \\
\hline Latin America-Caribbean & 10,500 & 5,200 & $-50.5 \%$ \\
\hline Middle East & 13,200 & 6,200 & $-53.0 \%$ \\
\hline North America & 34,700 & 18,300 & $-47.3 \%$ \\
\hline World & 171,900 & 74,500 & $-56.7 \%$ \\
\hline
\end{tabular}

Figure 1. Impact on Revenues in COVID-19.

The discussion has also highlighted that COVID 19 crises has deep impact on airport development which is divided into various categories for example, first of all due to COVID 19 crises, air travel was banned for specific period of time such as in strict lockdown situation which has caused total ground of air traffic for some time until permission is given to fly with SOPs. Similarly, a significant fall in revenue is seen in all most every revenue streams for example, aeronautical streams as well as non-aeronautical streams. Additionally, the section has also discussed upcoming challenges which air travel industry of Asia Pacific region has to face in post COVID 19 crises.

\section{Future Research Recommendations}

Despite the increase in a number of air traffic, aviation industry required more space for airports and the lands for the aircraft industry. In today's world, the mobility of air increases the impact of travelling, reduces the time with costeffectiveness. Where's the number of aircraft in 10-15 years will double. To handle the growth of air traffic, the air management system across the world must shift towards a more scalable model: requiring a digital system that is able to manage the increased activity of flights more effectively. The answer to manage the challenge of air traffic is UTM (Unmanned Traffic Management). It should be a framework that must be designed as such it is a networked collection of services that join together based on common rules. It is the need of aviation industry to break form traditional centralized control system. UTM is a system that should work on principle of distributed authority. Enabling more service providers to benefit as market evolves with time. The idea of decentralization will ease the monetary burden of services aviation from governments whilst remaining as regulators for security, access, and equity. Giving a chance to private companies to harmonize the system to ensure more operability across the world.

\section{References}

[1] Forrester, M. A., Sullivan, and C, editors. Doing quali- tative research in psychology: A practical guide. SAGE Publications Limited, 2018. 
[2] M Bengtsson "How to plan and perform a qualitative study using content analysis". Nursing Plus Open, 2: 8-14, 2016.

[3] Lisa M. Ellram and Wendy L. Tate "The use of sec-ondary data in purchasing and supply management $(\mathrm{P} / \mathrm{SM})$ research". Journal of Purchasing and Supply Management, 22 (4): 250 254, 2016.

[4] Stefan Tuchen, Mohit Arora, and Lucienne Blessing "Airport user experience unpacked: Conceptualizing its potential in the face of COVID-19". Journal of Air Transport Management, 89: 101919-101919, 2020

[5] S Nižetic' "Impact of coronavirus (COVID-19) pan- demic on air transport mobility, energy, and environ- ment: A case study". International Journal of Energy Research, 2020.

[6] Ryosuke Yashiro and Hironori Kato "Intermodal Connection of High-Speed Rail with Interregional Bus Services in Japan". Transportation Research Record: Journal of the Transportation Research Board, 2674 (11): 674-684, 2020.

[7] S Kaltenhaeuser, T Luchkova, N Klay, and R B R Ang, 2019. Assessment of the Impact of Air Launch Operations on Air Traffic in Europe.

[8] P J Hylton, 2018. Electronic retail effects on airports and regional development (Doctoral dissertation, Georgia Institute of Technology).

[9] Stefano Maria Iacus, Fabrizio Natale, Carlos Santa- maria, Spyridon Spyratos, and Michele Vespe "Es- timating and projecting air passenger traffic during the COVID-19 coronavirus outbreak and its socio- economic impact". Safety Science, 129: 104791-104791, 2020.

[10] W. H. Wong, Tommy Cheung, Anming Zhang, and Yue Wang "Is spatial dispersal the dominant trend in air transport development? A global analysis for 2006-2015". Journal of Air Transport Management, 74: 1-12, 2019.

[11] Suchithra Rajendran and Sharan Srinivas "Air taxi ser- vice for urban mobility: A critical review of recent developments, future challenges, and opportunities". Transportation Research Part E: Logistics and Trans- portation Review, 143: 102090 102090, 2020.

[12] H An, N King, and S O Hwang "Issues and solu- tions in airtraffic infrastructure and flow management for sustainable aviation growth: a literature review". World Review of Intermodal Transportation Research, 8 (4): 293-319, 2019.

[13] T V Kumar. Smart metropolitan regional develop- ment: economic and spatial design strategies. In Smart Metropolitan Regional Development, pages 3-97. Springer, 2019.

[14] Omar Netto, Jorge Silva, and Maria Baltazar "The air- port ACDM operational implementation description and challenges". Journal of Airline and Airport Man- agement, 10 (1): 14-14, 2020.

[15] S Suzuki and P Nijkamp, 2017. Regional performance measurement and improvement. Springer.
[16] Sunkyung Choi and Shinya Hanaoka "Diagramming development for a base camp and staging area in a humanitarian logistics base airport". Journal of Hu- manitarian Logistics and Supply Chain Management, 7 (2): 152-171, 2017.

[17] Gisle Solvoll, Terje Andreas Mathisen, and Morten Welde "Forecasting air traffic demand for major infras- tructure changes". Research in Transportation Eco- nomics, 82: 100873-100873, 2020.

[18] K R Cox, 2016. The politics of urban and regional development and the American exception. Syracuse University Press.

[19] X Ji "Promoting regional development bank complementarity: challenges to Asia and lessons from Eu- rope". Asia Europe Journal, 15 (3): 261-281, 2017.

[20] S Liu, Y Wan, H K Ha, Y Yoshida, and A Zhang "Im- pact of high-speed rail network development on airport traffic and traffic distribution: Evidence from China and Japan". Transportation Research Part A: Policy and Practice, 127: $115-135,2019$.

[21] A Otsuka "Regional determinants of total factor pro- ductivity in Japan: stochastic frontier analysis". The Annals of Regional Science, 58 (3): 579-596, 2017.

[22] D Yoon "The regional-innovation cluster policy for R\&D efficiency and the creative economy". Journal of Science and Technology Policy Management, 2017.

[23] M T P Coelho, J F M Rodrigues, A M Medina, P Scalco, L C Terribile, and B Vilela.

[24] B A Wright and M O Hague "The US-japan Alliance: Sustaining the Transformation". Joint Force Quarterly, 44: 59$59,2007$.

[25] K Yamaguchi "Inter-regional air transport accessibility and macro-economic performance in Japan". Trans- portation Research Part E: Logistics and Transportation Review, 43 (3): 247-258, 2007.

[26] L E Rocha "Dynamics of air transport networks: A re- view from a complex systems perspective". Chinese Journal of Aeronautics, 30 (2): 469-478, 2017.

\section{Biography}

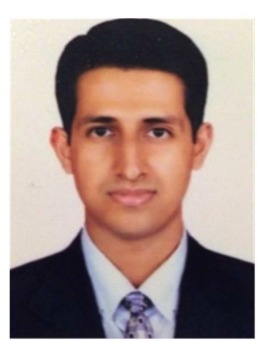

Kosuke Sendo, Boeing 777 and B737, Flight Operations Department, Airline Pilot A. T. P. L Education: Working towards a Ph.D. in Airport Development. Formerly worked as a Pilot Instructor at Department of Education, Osaka Aviation Technical Collage, Osaka Japan. Research area: Reynolds Number, Boundary Layer Control, Human Factors, Flight Dynamics, Airline Management, and Airport development. 